\title{
Ciencia y Tecnología para la Salud Visual y Ocular
}

2020-03-24

\section{Profesionalismo, más allá de la competencia clínica}

Nancy Piedad Molina-Montoya

Universidad de La Salle, Bogotá, revistasaludvisual@lasalle.edu.co

Follow this and additional works at: https://ciencia.lasalle.edu.co/svo

Part of the Eye Diseases Commons, Optometry Commons, Other Analytical, Diagnostic and Therapeutic Techniques and Equipment Commons, and the Vision Science Commons

\section{Citación recomendada}

Molina-Montoya NP. Profesionalismo, más allá de la competencia clínica. Cienc Tecnol Salud Vis Ocul. 2020;(2): 7-9. doi: https://doi.org/10.19052/sv.vol17.iss2.1

This Editorial is brought to you for free and open access by the Revistas científicas at Ciencia Unisalle. It has been accepted for inclusion in Ciencia y Tecnología para la Salud Visual y Ocular by an authorized editor of Ciencia Unisalle. For more information, please contact ciencia@lasalle.edu.co. 


\section{Editorial}

\section{PROFESIONALISMO, MÁS ALLÁ DE LA COMPETENCIA CLÍNICA}

Entre los aspectos diferenciales más sobresalientes de un profesional en cualquier área están: 1) brindar un servicio importante para la sociedad y haber recibido un entrenamiento formal extensivo y práctico, que suele implicar varios años de formación universitaria y un periodo de práctica supervisada antes de ejercer la disciplina; 2) tener una base de conocimientos complejos y un conjunto de habilidades especiales que requieren un juicio considerable y la realización de tareas no mecanizadas; 3) recibir formación continuada, actualizar constantemente los conocimientos y estar asociados a colegios o asociaciones que regulan el ejercicio de la profesión y que hacen cumplir las normas técnicas y éticas entre sus miembros; 4) reconocer una responsabilidad especial para con el público y con la sociedad, ya que forma parte de un contrato tácito que establece las obligaciones y compromisos entre las partes (1).

En coherencia con lo anterior, la optometría es una profesión de la salud y los retos y oportunidades que plantea su ejercicio, de cara al futuro, implican la necesidad de que los optómetras adopten un enfoque de atención centrado en el cuidado del paciente, que retome los valores esenciales de la profesión. En ese contexto, el profesionalismo se vislumbra como una clave para los tiempos venideros, que lleva implícita la idoneidad técnica en conjunto con un cúmulo de virtudes, aptitudes, atributos y competencias que definen el conjunto de obligaciones éticas y sociales especiales con los pacientes.

No es suficiente con ser buen clínico. Se necesita ser buena persona, cultivar los valores y virtudes de la profesión y desplegarlos en la atención y en el cuidado de la salud. Al respecto, Cruess, Cruess y Johnston (2) afirman que la capacidad profesional en ciencias de la salud está formada por tres competencias: la clínica, integrada por la evaluación y el juicio clínico; la general, en la que están implícitas habilidades de comunicación, pensamiento crítico y resolución de problemas, y, por último, la moral, en la que se cuentan la capacidad de vivir dentro de un esquema de valores morales y la responsabilidad personal (2). Epstein

y Hundert (3), en su definición de competencia profesional, retoman los mismos elementos, destacando el papel de las emociones, los valores y la reflexión en la práctica diaria en beneficio de los pacientes y la 
sociedad. A este respecto, el Colegio de Optometría de Reino Unido define al optómetra profesional como aquel

[...] que es honesto y está bien informado, que actúa éticamente por el mejor interés de los pacientes, mediante la aplicación de sus conocimientos y el mejoramiento de su competencia y juicio crítico, la comunicación efectiva con los pacientes, colegas, otros profesionales de la salud y los miembros de la comunidad, siguiendo activamente la orientación profesional. (4)

En línea con esa definición, las cualidades asociadas al profesionalismo en optometría son la comunicación asertiva, la ética, la honestidad, la integridad, el conocimiento, la confiabilidad y la atención centrada en el paciente (4). Los optómetras tienen el deber de cuidar los mejores intereses de sus pacientes con respecto a los ojos, la visión, la salud general, el bienestar y la calidad de vida. La ética profesional garantiza la competencia clínica y conduce a la aplicación de conocimientos especializados y habilidades con características como el compromiso y la responsabilidad profesional.

Por todo lo anterior, es necesario volver una y otra vez al código de ética de la profesión que está basado en los principios nucleares de la ética sanitaria y que conserva la esencia del juramento hipocrático.

Nuestro compromiso es privilegiar la salud de nuestros pacientes por encima de todo, brindar una atención idónea y concienzuda al máximo alcance de nuestra competencia, con preocupación, compasión y respeto a la dignidad de nuestros pacientes, ciñéndonos a estándares éticos, con honestidad; comprometiéndonos continuamente al perfeccionamiento de nuestros conocimientos y habilidades al servicio del paciente y, por último, sirviendo a nuestro país y a la humanidad como ciudadanos y como optómetras. En resumen, siendo profesionales en el ejercicio de nuestra disciplina.

Es necesario educar para el profesionalismo. No obstante, aprenderlo es un proceso largo que lleva tiempo y que requiere una práctica reflexiva que no depende exclusivamente de la persona, sino de diversos actores (instituciones académicas, empleadores y grupos de pares) que desempeñan un papel crítico en su desarrollo, fomento y mantenimiento.

Vale la pena invertir tiempo y esfuerzo en educar optómetras que actúen con profesionalismo. Este es un ideal que debe mantenerse y que todos los pacientes deben esperar, debido a que forma parte de un contrato tácito que establece las obligaciones y compromisos entre este y la sociedad. 


\section{REFERENCIAS}

1. MacDonald C. Professionalism and professional ethics: a distance education module prepared for the College of Optometrists of Ontario. Ontario; 2003.

2. Cruess RL, Cruess SR, Johnston SE. Professionalism: an ideal to be sustained. Lancet. 2000;356(9224):156-9.

3. Epstein RM, Hundert EM. Defining and assessing professional competence. JAMA. 2002;287(2):226-35.

4. College of Optometrist. Professionalism in optometry. Reino Unido: autor; 2014.

NANCY PIEDAD Molina-Montoya Editora jefe

Revista Ciencia y Tecnología para la Salud Visual y Ocular https://orcid.org/0000-0001-5239-1304

Cómo citar: Molina-Montoya NP. Profesionalismo, más allá de la competencia clínica. Cienc Tecnol Salud Vis Ocul. 2019;17(2):7-9. https://doi.org/10.19052/sv.voll7.iss2.1 